\title{
Mecânica Clássica: O Processo de Medida
}

\author{
Mario Cezar Bertin ${ }^{1}$ \\ ${ }^{1}$ Instituto de Física, Universidade Federal da Bahia
}

21 de setembro de 2020

\section{Interação do observador com o sistema}

Para o observador, realizar uma medição é interagir com o sistema. Como o observador também é um sistema físico, portanto, feito de partículas em interação, a interação pode mudar o estado de movimento de ambos os sistemas. No entanto, na mecânica clássica essa interação pode ser muito pequena. A medida ideal é aquela em que o observador e o sistema estão isolados um do outro e é assim que os físicos acreditavam ser a natureza da medida até o surgimento da mecânica quântica. No mundo real, é impossível medir sem interagir.

Digamos que queremos coletar informações sobre uma bola de futebol. Os dados podem ter, novamente, sobre sua cor. A primeira coisa que poderíamos fazer é lançar luz sobre a bola, de modo que o sistema que interage diretamente com a bola é um feixe de luz branca. A luz em si é um sistema físico, mas não mecânico. Pode ser vista aqui como uma onda de campo eletromagnético, certamente fora do domínio da mecânica clássica. Mas este é um caso em que podemos usar a descrição clássica de partículas para discutir o assunto em questão. Para coletar a medida, no entanto, o observador deve, de alguma forma, interagir com a luz espalhada pela bola, talvez com uma câmera. A câmera também deve enviar informações para um computador, para a resposta final sobre a cor da bola. Obviamente, a câmera pode ser substituída por um olho humano e o computador pode ser substituído por um cérebro humano.

A interação pode ser negligenciável, dependendo das propriedades do feixe e da 
bola. Normalmente, podemos ajustar a intensidade da luz para que a interação se torne fraca demais para resultar em alterações mensuráveis no estado da bola. Portanto, podemos usar essa configuração para medir a cor sem interferência sensível do processo de medição.

Por outro lado, se aumentarmos a intensidade da luz, as características da bola passam a sofrer interferência da própria medição. Conseqüentemente, medir a cor de uma bola com luz muito intensa destruirá as informações que você deseja coletar em primeiro lugar. Sabemos que um feixe suficientemente forte pode incendiar uma bola.

Na mecânica clássica, sempre supomos que a interação entre o observador e o sistema físico possa ser arbitrariamente negligenciável. No entanto, veremos o colapso dessa suposição se o sistema for, por exemplo, muito pequeno em comparação com a influência do aparelho de medição. Medir a cor de um elétron usando o mesmo procedimento será impossível, pois mesmo a luz mais fraca irá interagir com o elétron, alterando a própria característica que o observador deseja medir. Para sistemas quânticos, a interação do observador com o sistema é sempre esperada; portanto, o que pode ser medido é a resposta do sistema ao ato de medição.

\section{A natureza estatística da medida}

Definimos a medida como um processo de filtragem de um único valor, ou um subconjunto de valores de um espectro, que é o conjunto de todas as medidas possíveis. É uma importante questão filosófica qual dos valores é a medida "verdadeira" do observável, ou mesmo se podemos falar de uma medida "verdadeira". É possível adotar o ponto de vista platônico na mecânica clássica, que é a existência de um valor real para o observável. Nesse caso, experimentos repetidos têm o objetivo de nos aproximar da medida "verdadeira", uma vez que uma única observação sempre tem um erro a ser considerado.

No entanto, essa abordagem do processo de medição encontra sérias dificuldades na física quântica, onde o resultado de um experimento pode depender do observável. Essa é a origem, por exemplo, da conhecida dualidade ondapartícula, observada em experimentos de dupla fenda. Uma teoria geral da me- 
dida não pode confiar na suposição da existência de uma medida "verdadeira".

Nesse caso, assumimos que o resultado de uma medição de um observável é aleatório dentro da faixa do espectro. Isso significa que uma única medição pode selecionar qualquer valor do espectro e não há como prever o resultado. Não existe uma medida "verdadeira". O melhor que podemos fazer é realizar várias medições em sequência, sempre tomando cuidado, para que o sistema físico seja inicialmente definido para o mesmo estado físico inicial.

Portanto, é possível realizar uma única medição, mas devemos fazer um número maior de medições antes de estabelecer um valor único para a medida. Este valor único é assumido como sendo o valor médio e um erro é atribuído ao desvio médio padrão, por exemplo.

\section{O experimento da dupla fenda}

Uma boa oportunidade de averiguar os limites do conceito clássico de partícula e do processo clássico da medida é a análise do caso do experimento de dupla fenda. As teorias corpuscular e ondulatória da luz nasceram aproximadamente ao mesmo tempo, no fim do século XVII e início do século XVIII, opondo defensores de ambas as vertentes de pensamento. A teoria corpuscular é atribuída a Newton (Newton, 1979), enquanto Descartes e Huygens deram origem à teoria ondulatória (Sabra, 1981) poucos anos antes. O experimento de dupla fenda, realizado primeiro por Thomas Young em 1800, possui diversas variações e seus resultados deram vitória à hipótese ondulatória sobre a proposta corpuscular para a natureza da luz.

No experimento original, Young reflete a luz do sol através de um espelho móvel sobre um pequeno buraco em uma folha de papel, de modo a obter um feixe de luz aproximadamente colimado. Este feixe é, então, dividido por um cartão de papel muito fino e projetado em um anteparo. $\mathrm{O}$ experimento também pode ser feito com a luz do sol passando através de um cartão com duas fendas estreitas e separadas por poucos milímetros, para dentro de uma câmara escura, como em (The Original Double Slit Experiment, n.d.). No entanto, a versão moderna do experimento é realizada com um laser que passa por um cartão com a dupla fenda e, subsequentemente, encontra um anteparo mais adiante. 
Se a luz fosse formada por partículas clássicas, o laser funcionaria como um canhão de partículas, disparando os fótons (partículas de luz) sobre o cartão com as fendas. Cada fóton interage com o cartão de duas formas diferentes. Ele é barrado pelo cartão caso não encontre uma fenda, ou passa livremente pelo cartão ao atingir exatamente a localização de uma fenda, caso a largura da fenda seja maior que a partícula. Portanto, um fóton pode passar por uma ou outra fenda, ou não passar pelo cartão. No anteparo, a colisão dos fótons com um filme fino revela a posição em que a partícula foi detectada. Neste caso, esperase que a imagem formada seja semelhante à fig. 1 .

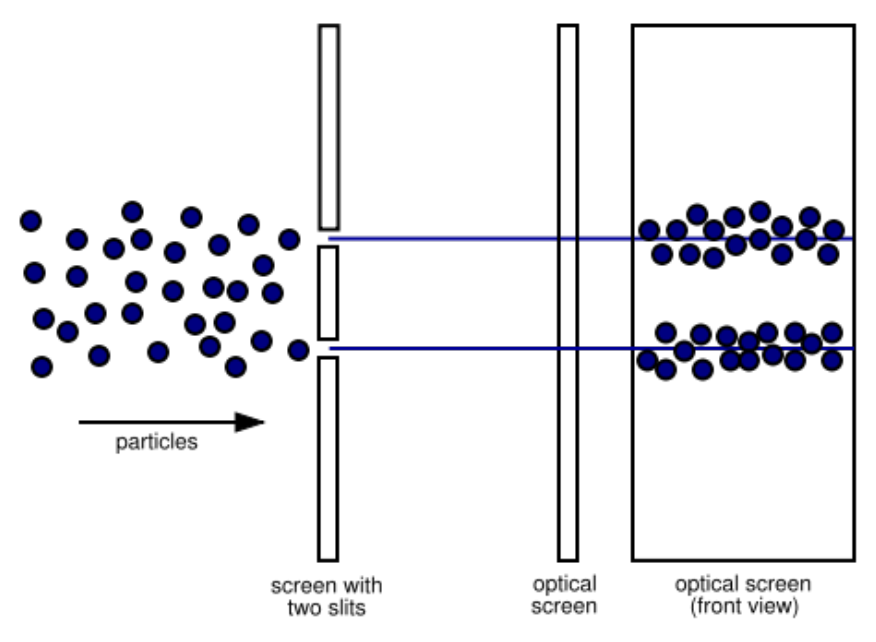

Figura 1: Resultado esperado do experimento de dupla fenda para partículas.

O observado, contudo, segue o padrão da fig. 2:

$\mathrm{Na}$ imagem formada pelo experimento, nota-se a formação de um padrão de interferência apenas explicável se a luz for composta por ondas. Dois fenômenos ondulatórios podem ser observados se a definição da imagem for suficientemente boa: a difração e a interferência. O padrão apresenta imagens múltiplas da fonte com luminosidade decrescente a medida que se afasta do centro da tela. Em cada imagem, caso a resolução seja boa, pode-se ver um padrão de franjas claras e escuras.

Portanto, a luz não pode ser formada por partículas clássicas. Contudo, ainda seria possível que o fenômeno da propagação da luz como onda pudesse ser compreendido dentro do escopo da mecânica clássica, visto que outros fenômenos 


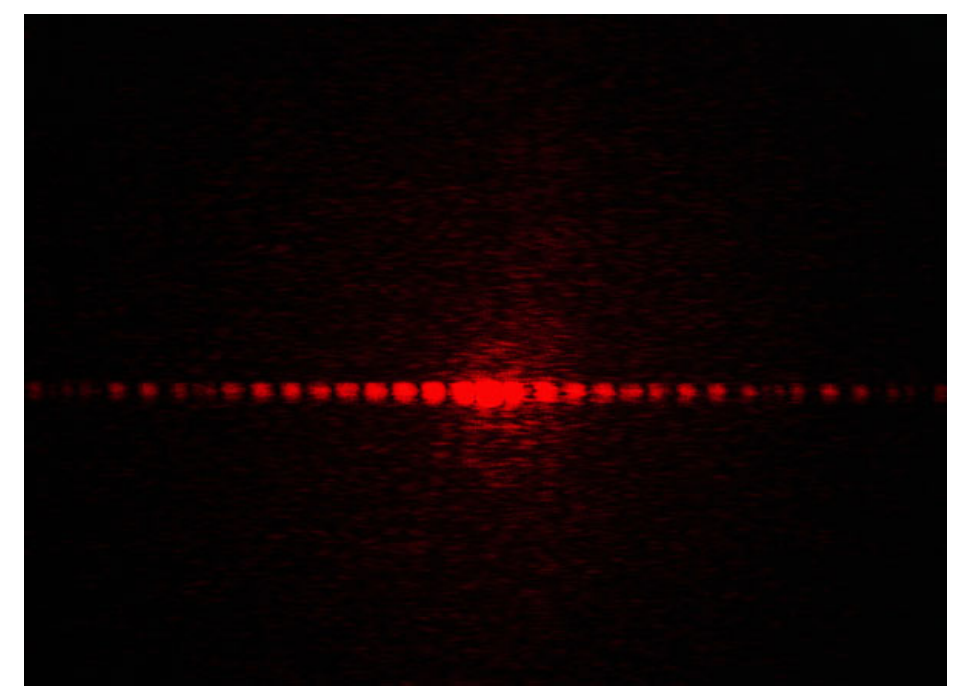

Figura 2: Imagem do experimento de dupla fenda.

ondulatórios são evidentemente mecânicos, como o caso das ondas sonoras e das ondas em superfícies líquidas. Nestes casos, um meio material (formado por partículas clássicas) fornece o substrato pelo qual ondas mecânicas se formam e se propagam. Assim, ao introduzir sua teoria eletrodinâmica e utiliza-la para demonstrar que a luz é uma onda eletromagnética, Maxwell (Maxwell, 2009) incorporou à teoria o conceito do éter. Originalmente, as ondas eletromagnéticas eram descritas como ondas mecânicas que se propagavam sobre o éter.

Contudo, o éter não demorou a ser descartado como um conceito necessário à teoria eletromagnética, de modo que a eletrodinâmica clássica descreve a luz como uma onda formada por campos elétricos e magnéticos transversais em propagação, sem a necessidade de um meio mecânico. Portanto, este ponto de vista não permite que o conceito clássico de partícula seja aplicável. É necessário que o conceito de campo também seja incluído na teoria.

\section{A dualidade onda-partícula}

Contudo, pode ser mais surpreendente o fato de que o mesmo experimento foi e continua sendo utilizado para testar outra hipótese, que surgiu com a tese de doutorado de Louis de Broglie em 1924, a de que toda partícula possui um comprimento de onda associado (Broglie, 1925). Assim, segundo esta hipótese, a matéria pode também apresentar comportamento ondulatório. 
Se em vez de um laser um canhão de elétrons for utilizado contra um anteparo com duas fendas estreitas, os mesmos padrões de interferência serão observados (fig. 3) (THOMSON \& REID, 1927).

Figura 3: Padrão de interferência de elétrons.

Ou seja, um feixe de elétrons apresenta o mesmo comportamento de um feixe de ondas no experimento de dupla fenda. Neste caso, o elétron também não pode ser descrito por uma partícula clássica. Poderíamos imaginar que esta seria uma propriedade exclusiva dos elétrons, ou que alguma interação não conhecida entre elétrons de um mesmo feixe causasse um efeito estatístico sobre a tela. Contudo, tem sido demonstrado ao longo dos anos que o padrão de dupla fenda é reproduzido por átomos e moléculas cada vez maiores (Fein et al., 2019).

Contra o argumento de o padrão de interferência para partículas de matéria ser fruto de um comportamento estatístico emergente, existe o fato de que o mesmo padrão se repete caso o canhão de partículas atire um elétron por vez, como mostra a fig 4.
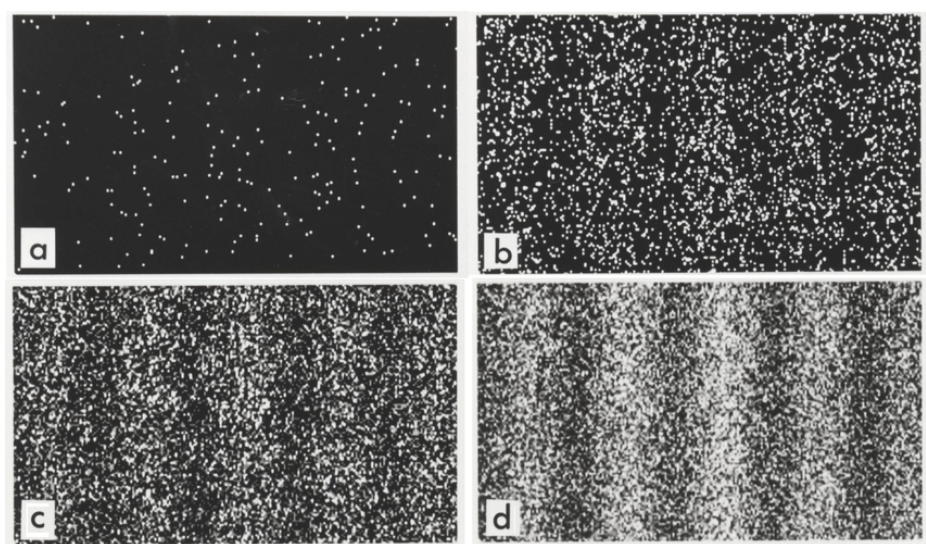

Figura 4: Padrão de interferência de elétrons em experimento de dupla fenda do tipo one-by-one.

Embora cada elétron atinja a tela como uma partícula clássica, a formação do padrão de interferência final sugere que o elétron passa pelas duas fendas como uma onda. Este problema tornou-se conhecido como a dualidade onda-partícula. 
A dificuldade em reconhecer a dualidade onda-partícula como um fenômeno natural ainda leva alguns a tratar deste problema como um paradoxo. $\mathrm{O}$ paradoxo decorre do fato de que estamos bem familiarizados com o conceito clássico de partícula, por um lado, e também com o conceito de campo clássico, por outro lado. Ambos os conceitos são excludentes na física clássica. Contudo, a física quântica é a teoria adequada para descrever e interpretar o experimento de dupla fenda. E a física quântica rompe com os conceitos clássicos de campos e partículas.

\section{Variações do experimento de dupla fenda e o papel do observador}

Também podemos aprender algo sobre a medida como interação do observador com o sistema físico através do experimento de dupla fenda. É possível, por exemplo, posicionar um detector antes do feixe (de fótons ou elétrons) atingir a dupla fenda, a fim de se saber de antemão se a partícula passará pela fenda da esquerda ou da direita, em uma variação do experimento chamada Which-Way. Esta medida pode ser feita sem alterar a trajetória da partícula individualmente.

Em um experimento Which-Way, podemos começar deixando o detector desligado, de modo que o feixe de partículas passe pelas fendas e resulte no padrão de interferência do experimento de dupla fenda ordinário. Ao ligar o detector, o observador adiciona ao sistema o elemento da medição. Como resultado, o padrão de interferência se desfaz e a tela reproduzirá o padrão esperado por partículas clássicas (fig ??). Se desligarmos o detector, o padrão de interferência será recomposto.

Rich media available at https://www. youtube.com/watch?v= qCmtegdqO०A

Uma segunda variação, conhecida como Delayed Choice, posiciona o detector entre as fendas e a tela, de modo que o detector poderá medir por qual fenda a partícula passou. Novamente, mas não de forma previsível segundo nossas concepções clássicas, o padrão de interferência é destruído. Esta versão do experimento de dupla fenda é ainda mais contraditória com o padrão clássico, visto que os fótons ou elétrons já atravessaram as fendas antes de serem detecta- 
dos pelo detector. $\mathrm{O}$ resultado significa que a detecção a posteriori modificou o caminho passado das partículas? Poderia ser um sinal de quebra de causalidade?

A resposta para essas questões foge ao nosso escopo. Contudo, parte do problema está em pressupostos escondidos carregados pelos conceitos clássicos de partículas, ondas, e pela forma como descrevemos classicamente o movimento desses objetos. Em primeiro lugar, ainda que didaticamente eficiente, a representação os fótons ou elétrons como frentes de onda que se propagam no espaço, como o caso do vídeo da fig. ??, não reflete a descrição quântica. De fato, o experimento de dupla fenda usual é um sistema estacionário, portanto, independente do tempo. É apenas uma ilusão a visão de elétrons e fótons partindo do canhão, passando pelas fendas e atingindo a tela como eventos sucessivos no tempo. A segunda ilusão é carregar para este problema nossas concepções de localidade clássicas. Os fenômenos quânticos, pelo contrário, são não locais.

Uma terceira questão é ainda mais importante. A mecânica quântica de Schrödinger e Heisenberg não é a teoria fundamental por trás dos fenômenos quânticos. Assim, podemos estar utilizando a teoria e interpretação equivocadas para entender o que ocorre neste experimento em particular, assim como em outros. A teoria quântica de campos, na qual as partículas são conceitos derivados dos campos quânticos, é um cenário no qual os problemas de interpretação da mecânica quântica parecem se dirimir.

Para nós, a lição é a de que os conceitos e teorias clássicas possuem validade restrita, que depende do tipo de sistema físico. Nossa tentativa de estabelecer os conceitos de partícula, interação e movimento, e o próprio conceito de medida como interação negligenciável do observador com o sistema, falham em um grande número de situações.

\section{Referências}

Opticks: or, A treatise of the reflections, refractions, inflections, and colours of light. (1979). Dover Pub. 
Theories of Light: From Descartes to Newton. (1981). Cambridge University Press.

https://www.youtube.com/watch?v=Iuv6hY6zsd0. https:// www youtube. com/watch?v=Iuv6hY6zsd0

Niven, W. D. (Ed.). (2009). The Scientific Papers of James Clerk Maxwell. Cambridge University Press. https://doi.org/10.1017/ cbo9780511698095

Recherches sur la théorie des Quanta. (1925). Annales De Physique, 10(3), 22-128. https://doi.org/10.1051/anphys/192510030022

Diffraction of Cathode Rays by a Thin Film. (1927). Nature, 119(3007), 890-890. https://doi.org/10.1038/119890a0

Quantum superposition of molecules beyond $25 \mathrm{kDa}$. (2019). Nature Physics, 15(12), 1242-1245. https://doi.org/10.1038/s41567-019$0663-9$ 